\title{
Nicotine Metabolite Ratio Measurement
}

National Cancer Institute

\section{Source}

National Cancer Institute. Nicotine Metabolite Ratio Measurement. NCI Thesaurus. Code C162518.

A measurement of the ratio of the nicotine metabolites 3-hydroxycotinine $(3 \mathrm{HC})$ to cotinine in a sample. 